\title{
The Role of the Medial Prefrontal Cortex in Innate Fear Regulation in Infants, Juveniles, and Adolescents
}

\author{
Thomas Chan, ${ }^{1,2}$ Kwaku Kyere, ${ }^{1,2}$ Brian R. Davis, ${ }^{1,2}$ Alexei Shemyakin,, ${ }^{1,2}$ Patricia A. Kabitzke, ${ }^{1,2}$ Harry N. Shair, ${ }^{1,2}$ \\ Gordon A. Barr, ${ }^{1,2,3}$ and Christoph P. Wiedenmayer ${ }^{\dagger 1,2}$ \\ ${ }^{1}$ Department of Psychiatry, Columbia University, New York, New York 10032, ${ }^{2}$ Division of Developmental Neuroscience, New York State Psychiatric \\ Institute, New York, New York 10032, and '3Department of Anesthesiology and Critical Care Medicine, Children's Hospital of Philadelphia and the \\ University of Pennsylvania School of Medicine, Philadelphia, Pennsylvania 19104
}

In adult animals, the medial prefrontal cortex (mPFC) plays a significant role in regulating emotions and projects to the amygdala and periaqueductal gray (PAG) to modulate emotional responses. However, little is known about the development of this neural circuit and its relevance to unlearned fear in pre-adulthood. To address these issues, we examined the mPFC of 14-d-old (infants), 26-d-old (juveniles), and 38- to 42-d-old (adolescents) rats to represent different developmental and social milestones. The expression patterns of the neuronal marker FOS were used to assess neurological activity. Muscimol, a GABA agonist, was used to inactivate the prelimbic and infralimbic mPFC subdivisions (400 $\mathrm{ng}$ in $200 \mathrm{nl}$ ). Animals were exposed to either a threatening or nonthreatening stimulus that was ecologically relevant and age specific. Freezing was measured as an indicator of innate fear behavior. The data indicated that the MPFC is neither active nor responsive to innate fear in infant rats. In juveniles, the prelimbic mPFC became responsive in processing aversive sensory stimulation but did not regulate freezing behavior. Finally, during adolescence, inactivation of the prelimbic mPFC significantly attenuated freezing and decreased FOS expression in the ventral PAG. Surprisingly, across all ages, there were no significant differences in FOS levels in the medial and basolateral/lateral amygdala when either $\mathrm{mPFC}$ subdivision was inactivated. Together, unlearned fear has a unique developmental course with different brain areas involved in unlearned fear in the immature animal than the adult. In particular, the mPFC neural circuitry is different in young animals and progressively develops more capacities as the animal matures.

\section{Introduction}

Animals continually monitor their environment and must respond appropriately to avoid being harmed, injured, or killed. They respond with defensive behaviors and fear if they perceive a stimulus to be dangerous. Animals possess a specialized neural circuit that allows them to assess the valence of sensory stimuli and to generate defensive responses if the stimulus poses a threat. This fear circuit consists of interconnected brain areas that include the medial prefrontal cortex (mPFC), the amygdala, and the periaqueductal gray (PAG), which participate in stimulus processing and the generation of defensive behavior (LeDoux, 2000; Öhman and Mineka, 2001; Rosen, 2004).

\footnotetext{
Received Oct. 4, 2010; revised Jan. 20, 2011; accepted Jan. 27, 2011.

This work was supported by National Institutes of Health Grants R21 MH073994, R01 MH071751, and ARRA R01 MH071751S1 (C.P.W.; supplement to K.K.). We thank the following for their contributions: Caity Schubmehl, Jesús Madrid, Chicora Oliver, Jeff Muller, Maria Milekic, Michael Myers, and the Department of Developmental Neuroscience at New York State Psychiatric Institute. Christoph Wiedenmayer died suddenly and unexpectedly in March, 2010. We are honored to have been part of Christoph's work and life. He will always be admired and remembered as a mentor, colleague, and friend. Requiescat in pace. Christoph P. Wiedenmayer, $7 / 16 / 58-3 / 20 / 10$. We dedicate this manuscript to the Wiedenmayer family.

${ }^{\dagger}$ Deceased, March 20, 2010.

The authors declare no competing financial interests.

This article is freely available online through the J Neurosci Open Choice option.

Correspondence should be addressed to Dr. Gordon A. Barr, Department of Anesthesiology and Critical Care Medicine, Children's Hospital of Philadelphia, ARC 716D, 3615 Civic Center Boulevard, Philadelphia, PA 19104. E-mail: barrg@email.chop.edu.

DOI:10.1523/JNEUROSCI.5216-10.2011

Copyright $\odot 2011$ the authors $\quad 0270-6474 / 11 / 314991-09 \$ 15.00 / 0$
}

It has been proposed that the MPFC regulates fear behavior by modulating the activity of the amygdala and PAG (Paré et al., 2004; Price, 2005; Peters et al., 2009; Ulrich-Lai and Herman, 2009). According to this model, two subdivisions of the mPFC play opposing roles in fear behavior regulation. The prelimbic subdivision promotes the expression of fear by increasing amygdala output. The infralimbic subdivision, conversely, exerts inhibitory control on fear expression by decreasing amygdala output. The infralimbic and the prelimbic mPFC also influence fear behavior through direct projections to columns of the PAG that generate defensive behaviors (An et al., 1998; Floyd et al., 2000; Keay and Bandler, 2001; Gabbott et al., 2005). Findings in adult rodents support this model: inactivation of the prelimbic $\mathrm{mPFC}$ decreased conditioned freezing and stimulation increased it, whereas stimulation of the infralimbic $\mathrm{mPFC}$ decreased freezing (Vidal-Gonzalez et al., 2006; Corcoran and Quirk, 2007).

Although animals are able to respond to threats throughout life, little is known about the role of the MPFC in fear regulation in young animals. Fear behavior changes dynamically during early development, with young animals exhibiting different fear reactivity than adult animals (Bronson, 1968; Curio, 1993; Wiedenmayer, 2009). Stimulus assessment is particularly demanding for animals in early development because a stimulus may pose a threat at one age but not at a later age. For example, an unfamiliar male conspecific poses a threat to infant but not juvenile rats (Wiedenmayer et al., 2005). Furthermore, the mPFC may not 
have the same regulatory function in early life as in adulthood because it continues to develop postnatally (van Eden et al., 1990; Benes et al., 2000). For example, the mPFC does not support fear memory extinction in infant rats but becomes functional only in juvenile rats (Kim et al., 2009).

The present study investigates whether the mPFC contributes to unlearned fear behavior in young rats and whether its function changes during development. In particular, we examine whether the two subdivisions have opposing roles in fear expression. Rats of three different age groups-infants, juveniles, and adolescents-were exposed to an age-specific threatening or nonthreatening stimulus, and the function of the MPFC was assessed. We hypothesized that mPFC subdivisions differentially regulate amygdala and PAG activity and thus fear responsivity and that the MPFC has this function in juvenile and adolescent rats but not in infant rats.

\section{Materials and Methods}

Animals. Male Long-Evans hooded rats were bred and housed in standard laboratory cages, which were maintained in a colony room with a temperature of $22-24^{\circ} \mathrm{C}$. The animals were given ad libitum access to food and water, and light in the room was set to a $12 \mathrm{~h}$ light/dark cycle with light onset at 6:00 A.M. Adult males and females were housed together for a 3 week period, and then the males were separated from the impregnated females. The cages of the impregnated females were checked daily, and rat pups found were considered as day 0 . Offspring were weaned at $23 \mathrm{~d}$ of age, and same-sex littermates were kept together in groups of two to four until the completion of the experiments. The age groups used spanned across three stages of ontogeny: 14-d-old rats [postnatal day 14 (P14)] as preweaned infants, P26 as weaned juveniles, and P40-P42 as adolescents.

Lactating females nursing infant pups, nonlactating females, and sexually experienced unfamiliar male rats were used as stimulus animals and were housed in the same room. All tests and treatment procedures were approved by and were in accordance with the Institutional Animal Care and Use Committee of New York State Psychiatric Institute.

Surgery. One day before testing, four male rats from each tested litter were randomly selected for bilateral intracranial cannula implantation surgery. All rats undergoing surgery were anesthetized with isoflurane (Henry Schein) mixed with oxygen and nitrous oxide, which was regulated by an Open Tabletop Isoflurane Vaporizing System (Stoelting Company). For surgery, rats were placed in a stereotaxic apparatus (Stoelting Company), which was fitted with an adapter for infant and juvenile rats.

For infant rats, bilateral burr holes were drilled $1.6 \mathrm{~mm}$ anterior and $1.9 \mathrm{~mm}$ lateral to bregma for the infralimbic $\mathrm{mPFC}$ and $1.6 \mathrm{~mm}$ anterior and $2.0 \mathrm{~mm}$ lateral to bregma for the prelimbic mPFC. Twenty-three gauge guide cannulas were then inserted to a depth of $4.2 \mathrm{~mm}$ for the infralimbic and $3.2 \mathrm{~mm}$ for the prelimbic mPFC. For juvenile rats, bilateral burr holes were drilled $2.0 \mathrm{~mm}$ anterior and $2.0 \mathrm{~mm}$ lateral to bregma for the infralimbic mPFC and $2.0 \mathrm{~mm}$ anterior and $2.2 \mathrm{~mm}$ lateral to bregma for the prelimbic mPFC. Twenty-three gauge guide cannulas were then inserted to a depth of $4.2 \mathrm{~mm}$ for the infralimbic and $3.3 \mathrm{~mm}$
B
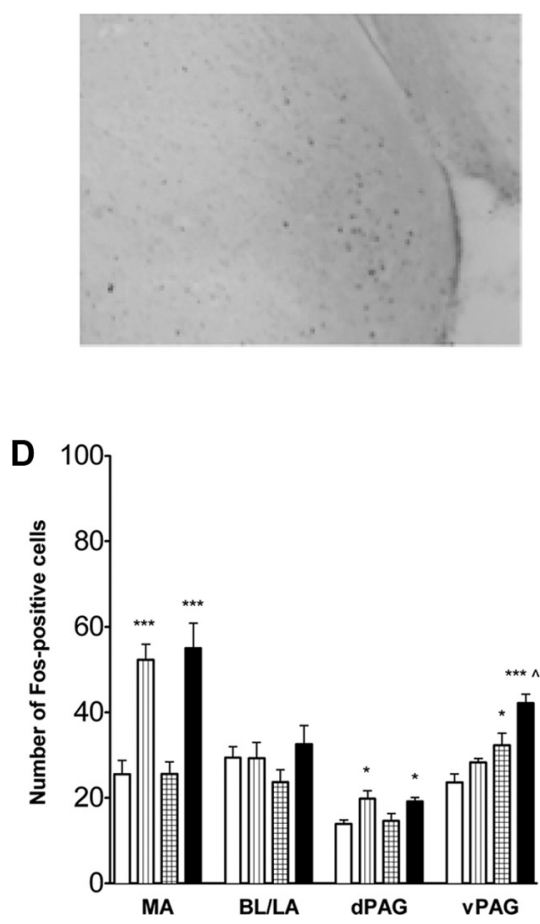

Figure 1. Fear response and FOS expression in infant rats with intact $\mathrm{mPFC}$. A, Percentage time freezing (mean $\pm \mathrm{SEM}$ ) during exposure to an adult female rat, cat fur odor, or an adult male rat. Controls were exposed to an empty cage. Male-exposed rats froze significantly more than cat-odor-exposed, female-exposed, or control rats ( $p<0.001$ for all). Pups exposed to the cat odor froze basolateral/lateral amygdala. $n=6-9$ for all conditions. ${ }^{* *} p<0.01,{ }^{* * *} p<0.001$ compared with controls; $\wedge p<0.05$ compared with control or female exposed. Note the $y$-axis scale differs for Figures 1,3 , and 5 for the prefrontal cortex FOS counts.

for the prelimbic mPFC. For adolescent rats, bilateral burr holes were drilled $2.6 \mathrm{~mm}$ anterior and $2.2 \mathrm{~mm}$ lateral to bregma for the infralimbic $\mathrm{mPFC}$ and $2.6 \mathrm{~mm}$ anterior and $2.5 \mathrm{~mm}$ lateral to bregma for the prelimbic mPFC. Twenty-three gauge guide cannulas were then inserted to a depth of $4.3 \mathrm{~mm}$ for the infralimbic and $3.5 \mathrm{~mm}$ for the prelimbic $\mathrm{mPFC}$. Vertical insertion of the cannulas into the infralimbic mPFC may damage the prelimbic $\mathrm{mPFC}$, and insertion into the prelimbic $\mathrm{mPFC}$ may damage the cingulate $\mathrm{mPFC}$. Therefore, for all ages, guide cannulas were inserted at a $24^{\circ}$ angle for the prelimbic $\mathrm{mPFC}$ and at $16^{\circ}$ angle for the infralimbic mPFC to prevent damage to overlying $\mathrm{mPFC}$ structures. The cannulas were secured to the skull with dental cement. Rats were returned to their home cage and littermates after they had recovered from the anesthesia. Rats gained weight between surgery and testing the next day, which suggests that the recovery was successful.

Testing procedure. Infant and juvenile rats were tested in groups of three to decrease isolation-induced stress, which itself can alter freezing (Hofer and Shair, 1980; Hennessy and Weinberg, 1990). At these ages, a single pup of the group of three was identified a priori to provide a single data point. When the pups were in different experimental conditions, each contributed to the data. Adolescent rats were tested individually. Infusions were given immediately before the start of the testing. Cannulated rats were infused with either $200 \mathrm{nl}$ of $400 \mathrm{ng}$ GABA agonist muscimol (Sigma-Aldrich) or $200 \mathrm{nl}$ of vehicle solution ( $0.9 \%$ saline). The 30 gauge injection cannula was connected to a $10 \mu$ l glass syringe (Hamilton Company) operated by hand and was left in the guide cannula for $30 \mathrm{~s}$ after the injection to permit maximal diffusion. Injection cannulas for all ages were constructed so that they extended $0.5 \mathrm{~mm}$ beyond the tip of the 

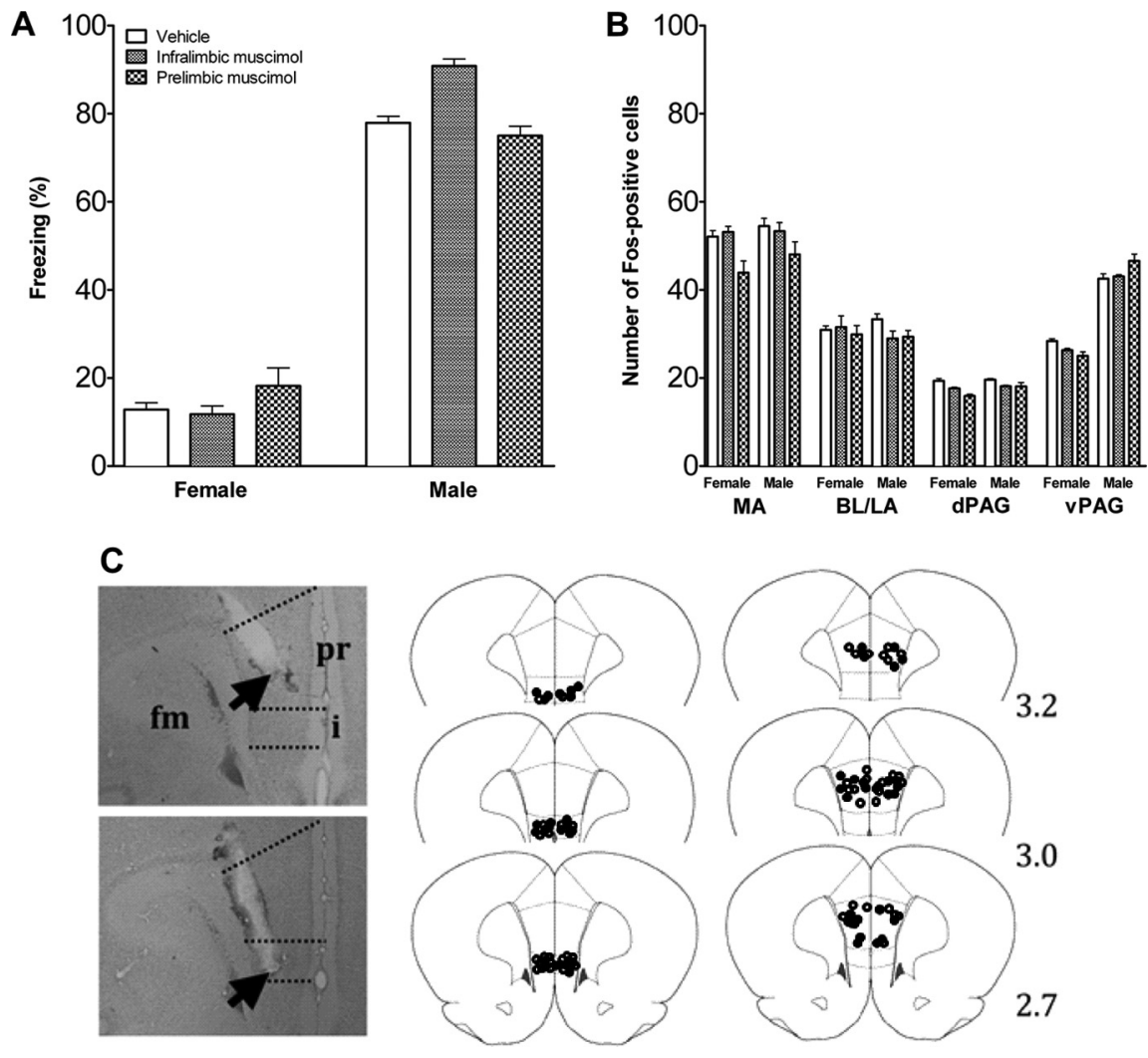

Figure 2. Fear response and brain activation in infant rats infused with muscimol or vehicle in mPFC. $A$, Percentage time freezing in infant rats infused with muscimol or vehicle in $\mathrm{MPFC}$ and exposed to a nonthreatening female or threatening male rat. Mean \pm SEM. $\boldsymbol{B}$, Number of FOS-positive cells in the amygdala and PAG of infant rats injected with vehicle or muscimol into infralimbic and prelimbic mPFC and exposed to a nonthreatening female or threatening male rat. Mean \pm SE. $n=6-9$ in each condition. C, Cannula placement in mPFC of infant rats. Photographs of cresyl-violet-stained sections with placement in prelimbic (pr) and infralimbic (i) mPFC. fm, Forceps minor corpus callosum; arrow, cannula tip. Drawing of placement in infralimbic (middle) and prelimbic (right) mPFC. Open circles represent the location of cannula tips in rats infused with vehicle; filled circles represent the location of cannula tips in rats infused with muscimol. Numbers indicate the distance in millimeters from bregma.

guide cannula. Previous radiolabeling results (Chen et al., 2006) found that this volume of muscimol spreads to a maximum radius of $0.5 \mathrm{~mm}$ from the cannula tip, restricting the pharmacological inactivation effect to the mPFC subdivisions. Cannula placements were verified in later histology procedures (see below).

After the infusion, each group or animal was placed into one compartment of a testing cage. A wire-mesh screen divided the testing cage $(46 \times$ $25 \times 21 \mathrm{~cm})$ into two equal compartments. The compartment containing the rats had soiled bedding collected from the home cage just before the test. The other compartment was used to present threatening and nonthreatening stimuli. Animals were given a $3 \mathrm{~min}$ adaptation period. Then the stimulus was placed in the experimental compartment for 5 min. In the control condition, the experimental compartment was left empty. After testing, rats were kept in holding cages until perfusion.

Use of age-specific ecological threatening or nonthreatening stimuli. We used different stimuli to provide age-appropriate threats. Thus, different stimuli were used at different ages. Had we used the same stimulus, for example the strange male, the resultant interaction would be different depending on age: the strange male is infanticidal for the $14 \mathrm{~d}$ old, neutral to the $26 \mathrm{~d}$ old, but a combatant for the adolescent. Similar changes occur in the response of the lactating female to different aged animals. Thus, we chose "functionally" neutral stimuli based on ecological criteria.

For infant rats, an unfamiliar, unrelated adult male rat or a cat odor was used as a threatening stimulus. Adult males are a significant threat to infant rats, because they often kill unrelated offspring during the suckling period (Rosenberg, 1974; Brown, 1986; Mennella and Moltz, 1988). Cats pose a less likely threat to infant rats that remain primarily in the burrow, but cat odor does elicit defensive behavior at this age (Wiedenmayer and
Barr, 2001). Cat odor was derived from a cat pad. The fleece pad $(38 \times 61 \mathrm{~cm}$; Flexi-mat $)$ had been used by cats as resting place for $\sim 12$ months and probably contained fur, skin, and gland secretions. The pad was cut in pieces $(9 \times 10 \mathrm{~cm})$ that were kept in Ziploc bags at $-80^{\circ} \mathrm{C}$. Several hours before the training, the pad was thawed and kept in a closed container. At the start of the training session, the cover of the container was removed and the container was placed on the stimulus side of the cage behind the mesh. An unfamiliar lactating female rat was used as the nonthreatening stimulus. Lactating females do not pose an infanticidal threat; in fact, lactating females behave maternally toward any pups (Beach and Jaynes, 1956).

For juvenile rats, an unfamiliar adult male rat was used as a nonthreatening stimulus. The danger of infanticide stops at weaning (van Schaik and Janson, 2000) and adult male rats do not pose a threat or attack juvenile rats (Paul and Kupferschmidt, 1975). Cat odor was used as described above as the threatening stimulus because young rats are exposed to multiple predatory species (Caro, 2005).

For adolescent rats, cat odor was again used as a threatening stimulus. Because rats of this age expand their home range and migrate away from their natal burrow environment, predation poses a significant threat to survival (Calhoun, 1963). A nonlactating female rat was used as a nonthreatening stimulus. Lactating females were not used because they exhibit aggression toward intruders to protect their pups (Neumann et al., 2001; Deschamps et al., 2003), and adult male rats were not used because they react to intruding adolescent males with aggression and may even kill them (Thor and Flannelly, 1976).

Immunocytochemistry. Two hours after testing, when FOS expression levels peak (Morgan and Curran, 1991), the rats were removed from the holding cage and given an overdose volume of sodium pentobarbital (Abbott Laboratories) or a ketamine $(100 \mathrm{mg} / \mathrm{kg})$ and xylazine $(15 \mathrm{mg} / \mathrm{kg})$ mixture. Transcardial perfusion of the rats was performed using a $4 \%$ paraformaldehyde solution (Electron Microscopy Sciences) as the fixative, and the brains were removed and stored in formalin overnight. The brains were placed in a $30 \%$ sucrose buffer for cryoprotection before they were frozen, and $30 \mu \mathrm{m}$ coronal sections were cut using a cryostat. Sections were collected for the prefrontal cortex, amygdala, and PAG in PBS. Free-floating brain sections were processed using a modified protocol provided by a commercial antibody staining kit (ABC kit, Vectastain Elite; Vector Laboratories), which uses the diaminobenzedine-peroxidase method of visualizing antigen-binding sites. The sections were first incubated for $48 \mathrm{~h}$ at $4^{\circ} \mathrm{C}$ in the primary antibody, rabbit anti-FOS $(\mathrm{H}$ 125; Santa Cruz Biotechnology), diluted 1:5000 in PBS with Triton X-100 and $1 \%$ normal goat serum. The sections were then rinsed and incubated with the secondary antibody (goat anti-rabbit; Vector Laboratories) for $1 \mathrm{~h}$ and processed using the $\mathrm{ABC}$ kit protocol. Stained sections were mounted on Vectabond-covered slides, dehydrated in alcohol, cleared in xylene, and coverslipped with DPX (Sigma-Aldrich).

FOS data acquisition and analysis. Positive labeled FOS-like immunoreactive cells were visualized using a microscope (Nikon Labophot-2) with a $20 \times$ objective attached to a digital camera (Nikon DS-Fi1) connected to a computer. The subdivisions of the mPFC, amygdala, and PAG were determined with the cresyl-violet-stained sections using an atlas of the rat brain (Paxinos and Watson, 2007). All FOS-positive cells were counted bilaterally in the relevant brain nuclei with NIS-Elements 
(Nikon) by an experimenter blind to the condition of the specimen. For a cell to be considered FOS positive, it had to be distinct from the background regardless of the intensity of the staining. The profiles of FOS-like immunoreactive cells in single optical planes were thus counted (Coggeshall and Lekan, 1996). Sections of different rats were matched for corresponding neuroanatomical levels, and the mean number of cell counts per brain area was calculated by averaging the counts from all sections of each animal.

Histology. To verify cannula placements, $50 \mu \mathrm{m}$ coronal sections were taken through the mPFC, mounted on glass slides, stained with cresyl violet, and coverslipped. Cannula placement was determined for each rat using a brain atlas (Paxinos and Watson, 2007).

Behavioral scoring. A digital camera (Sony DCR-SR45) was used to record behaviors. Video files were transferred to and scored in the Observer XT 7.0 (Noldus Information Technologies). The scorer was blind to all conditions. The dependent variable quantifying fear was freezing. Freezing was defined as any posture in which the pup did not exhibit any movement except that necessary for respiration and is expressed in the final analysis as a percentage of total observation time. In addition, we measured other exploratory behaviors including the following: walking and sniffing around the cage, rearing (standing on their hindlegs and sniffing around), sniffing and walking around specifically the wire mesh, rearing at the mesh, and social interaction with littermates.

Statistical analysis. All data were analyzed by factorial ANOVA. For the freezing behavior and FOS cell counts in intact animals, one-way ANOVAs were used with the stimulus type being the factor. Newman-Keuls tests were used for post hoc comparisons. In the studies in which either the prelimbic or infralimbic structures were inactivated by muscimol injection, freezing and FOS counts were analyzed by two-way ANOVAs with the factors being injection (vehicle/infralimbic, muscimol/infralimbic, vehicle/prelimbic, muscimol/prelimbic) and stimulus type. The Bonferroni's method was used for post hoc multiple comparisons in these analyses.

\section{Results}

Infant rats

\section{Behavior}

Infant rats with intact mPFCs were exposed to an age-specific threatening or nonthreatening stimulus, an unfamiliar adult male, cat odor, or a female rat. The behavioral response differed significantly across infant rats exposed to each of these stimuli (ANOVA, $F_{(3,23)}=21.0, p<0.001$ ). Infant rats exposed to the male froze significantly more than rats exposed to all other conditions and froze more to the cat odor more than to the female or the control condition (Newman-Keuls, $p<0.001$ for the male vs control, female, or cat odor; $p<0.05$ for cat odor compared with the control and female) (Fig. $1 A$ ). Control rats did not differ from female-exposed rats in their behavior.

\section{FOS cell counts}

A representative photomicrograph of FOS staining in the medial amygdala is shown in Figure $1 B$. The number of FOS-positive cells in the infralimbic and prelimbic mPFC did not differ between control, female-exposed, cat-odor-exposed, or maleexposed rats (Fig. 1C). To map activation of other areas of the fear circuit, FOS expression was assessed in the amygdala and PAG (Fig. 1D). Significant differences were found in the medial amygdala $\left(F_{(3,24)}=17.0, p<0.001\right)$, dorsal PAG $(\mathrm{dPAG})\left(F_{(3,24)}=\right.$ $10.3, p<0.001)$, and ventral PAG (vPAG) $\left(F_{(3,24)}=23.20, p<\right.$ $0.001)$. Female and male exposure increased the number of FOSpositive cells in the medial amygdala and APAG compared with cat odor or controls $(p<0.01)$, which did not differ from each other. Male exposure increased FOS-positive cells in the vPAG compared with cat-odor- or female-exposed and control rats $(p<0.001$ for each). Cat odor had higher levels of FOS-positive cells than did the controls $(p<0.05)$ but not the female. Females and controls did not differ. The number of FOS-positive cells did

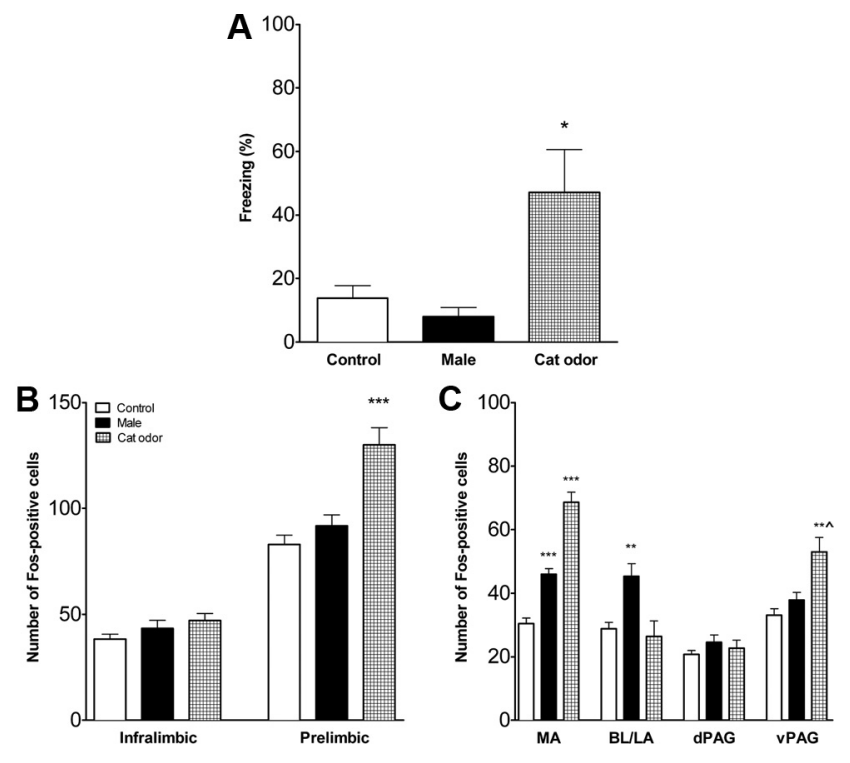

Figure 3. Fear response and FOS expression in juvenile rats with intact $\mathrm{mPFC}$. $\boldsymbol{A}$, Percentage time freezing (mean $\pm \mathrm{SE}$ ) during exposure to an adult male rat or cat fur odor. Controls were exposed to an empty cage. Cat-odor-exposed rats froze significantly more than male-exposed or control rats. $\boldsymbol{B}$, Activation of the $\mathrm{MPFC}$ in juvenile rats with intact mPFC. Number of FOSpositive cells (mean $\pm \mathrm{SE}$ ) was significantly increased in prelimbic $\mathrm{MPFC}$ of rats exposed to the threatening stimulus (cat odor). $C$, Activation of the amygdala and PAG in juvenile rats with intact mPFC. Exposure to the threatening stimulus (cat odor) increased the number of FOSpositive cells (mean $\pm \mathrm{SE}$ ) in the medial amygdala and ventrolateral PAG. Exposure to the nonthreatening stimulus (adult male) increased FOS in the medial and basolateral/lateral amygdala. MA, Medial amygdala; BL/LA, basolateral/lateral amygdala. ${ }^{*} p<0.05,{ }^{* *} p<0.01,{ }^{* * *} p<0.001$ compared with control; $\wedge p<0.01$ vs male exposure. $n=6-7$ in each condition.

not differ across stimulus conditions in the basolateral/lateral amygdala.

\section{Inactivation of the $M P F C$}

To examine whether the subdivisions of the MPFC are involved in fear regulation, the infralimbic and prelimbic $\mathrm{mPFC}$ were pharmacologically inactivated. Figure $2 C$ shows the cannula placements for cannulas implanted in an angle to prevent damage to the overlying $\mathrm{mPFC}$ subdivisions. Cannula tips were located in the infralimbic and prelimbic mPFC (Fig. 2C). Four rats were excluded because cannulas were located outside the target area. Inactivation of the infralimbic and prelimbic mPFC did not affect fear behavior (Fig. 2A) and did not affect activation of the projection areas. The number of FOS-positive cells in the amygdala and PAG did not differ between vehicle- and muscimol-injected rats (Fig. $2 B$ ).

\section{Juvenile rats}

Behavior

Juvenile rats with intact $\mathrm{mPFC}$ responded differently to cat odor, a male rat, or control (empty cage) $\left(F_{(2,18)}=6.5, p<0.01\right)$. Rats exposed to cat odor froze significantly more than rats exposed to the unfamiliar male rat or controls $(p<0.01$ and $p<0.05$, respectively) (Fig. $3 A$ ). Controls did not differ from maleexposed rats.

\section{FOS cell counts}

Exposure to the three stimuli differentially activated the subdivisions of the mPFC. There was no effect on the infralimbic mPFC, but there was a significant main effect for the prelimbic mPFC $\left(F_{(2,18)}=17.1, p<0.001\right)$. Cat-odor-exposed rats expressed significantly more FOS-positive cells than male-exposed or control 

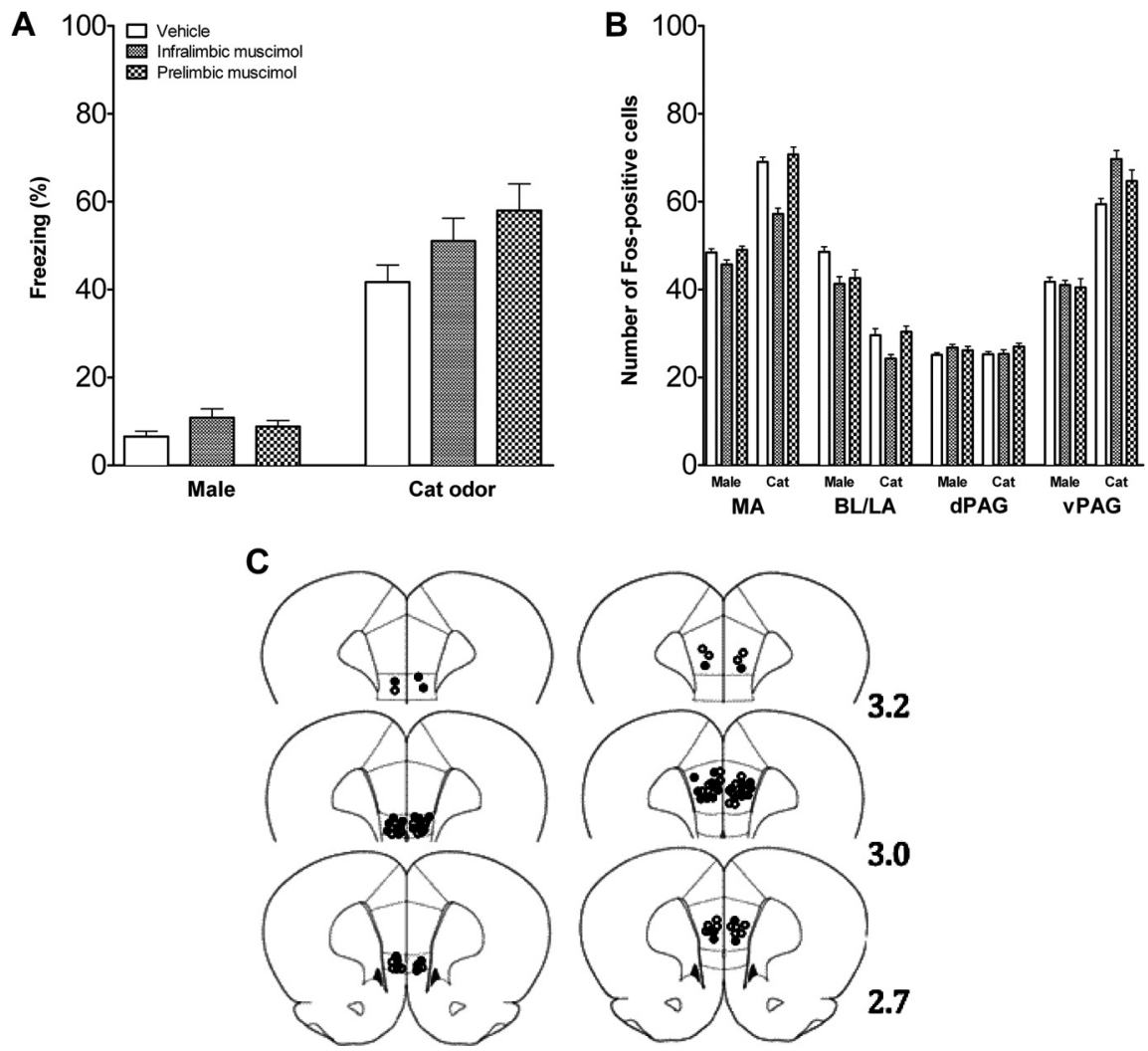

Figure 4. Fear response and brain activation in juvenile rats infused with muscimol or vehicle in $\mathrm{mPFC}$. $A$, Percentage time freezing in juvenile rats infused with vehicle or muscimol in $\mathrm{MPFC}$ and exposed to a nonthreatening male or threatening cat odor. Mean \pm SE. $\boldsymbol{B}$, Number of FOS-positive cells in the amygdala and PAG of juvenile rats injected with vehicle or muscimol into infralimbic and prelimbic mPFC and exposed to a nonthreatening male or threatening cat odor. Mean \pm SE. $n=6-7$ in each condition. C, Cannula placement in infralimbic (left) and prelimbic (right) mPFC of juvenile rats. Open circles represent the location of cannula tips in rats infused with vehicle, and filled circles represent the location of cannula tips in rats infused with muscimol. Numbers indicate the distance in millimeters from bregma.

rats $(p<0.001)$ (Fig. $3 B)$. The number of cells did not differ between male-exposed and control rats. FOS expression differed in the $\mathrm{mPFC}$ projection areas as well (Fig. $3 C$ ). Significant differences were found in the medial amygdala $\left(F_{(2,18)}=65.2, p<\right.$ $0.001)$, basolateral/lateral amygdala $\left(F_{(2,18)}=7.3, p<0.01\right)$, and $\operatorname{vPAG}\left(F_{(2,18)}=10.6, p<0.01\right)$. Cat-odor-exposed rats had significantly more FOS-positive cells in the medial amygdala than male-exposed $(p<0.001)$ and control $(p<0.001)$ rats, with male-exposed rats having higher expression than controls $(p<$ $0.001)$. Male-exposed rats had significantly more FOS-positive cells in the basolateral/lateral amygdala $(p<0.01)$. Cat-odorexposed rats had significantly more FOS-positive cells in the vPAG $(p<0.01)$ compared with control $(p<0.001)$ and maleexposed $(p<0.01)$ rats. There were no significant differences in the dPAG.

\section{Inactivation of the $m P F C$}

To investigate the role of the $\mathrm{mPFC}$ in fear regulation in juvenile rats, the infralimbic and prelimbic subdivisions were inactivated. The tips of the intracranial cannulas were located within the infralimbic and the prelimbic mPFC (Fig. 4C). Two animals were excluded because cannulas were placed outside target area. Muscimol or vehicle was infused, and rats were exposed to the adult male rat or cat odor. Inactivation of the infralimbic and prelimbic mPFC did not affect fear behavior (Fig. 4A) and did not affect levels of FOS expression in the projection areas (Fig. $4 B$ ).

\begin{abstract}
Adolescent rats
Behavior

Cat odor was used as threatening stimulus and an unfamiliar adult nonlactating female rat as a nonthreatening stimulus. Adolescent rats with intact mPFCs responded differently to the female rat, cat odor, and control (an empty cage) $\left(F_{(2,15)}=\right.$ $16.2, p<0.001)$. Rats exposed to cat odor froze significantly more than rats exposed to the female or controls $(p<0.001)$ (Fig. $5 A)$. Control rats did not differ from female-exposed rats.
\end{abstract}

\section{FOS cell counts}

Exposure to the three stimulus conditions differentially activated the subdivisions of the mPFC. There was no effect on the infralimbic $\mathrm{mPFC}$, but there was a significant main effect for the prelimbic mPFC $\left(F_{(2,15)}=17.7, p<0.001\right)$. In the prelimbic $\mathrm{mPFC}$, cat-odor-exposed rats expressed significantly more FOS-positive cells than female- or control-exposed rats $(p<0.001)$ (Fig. 5B). Number of cells did not differ between female-exposed and control rats. Significant differences were found in the medial amygdala $\left(F_{(2,18)}=\right.$ 25.4, $p<0.001)$, basolateral/lateral amygdala $\left(F_{(2,18)}=11.1, p<0.001\right)$, and $\operatorname{vPAG}\left(F_{(2,18)}=22.7, p<0.001\right)$. Catodor-exposed rats had significantly more FOS-positive cells in the medial amygdala than female-exposed $(p<0.001)$ and control-exposed $(p<0.001)$ rats, and female-exposed rats had significantly higher expression than controls $(p<$ 0.01) (Fig. 5C). Cat-odor-exposed rats had significantly more FOS-positive cells in the basolateral/lateral amygdala than controls $(p<0.001)$ and female-exposed rats $(p<0.01)$. There were no differences between control and female-exposed rats in the basolateral/lateral amygdala. Catodor-exposed rats had significantly more FOS-positive cells in the vPAG $(p<0.001)$ compared with control and femaleexposed rats. There were no differences in the dPAG.

\section{Inactivation of the $M P F C$}

The infralimbic and prelimbic subdivisions were pharmacologically inactivated to assess their role in fear regulation. The tips of the intracranial cannulas were located within the infralimbic and the prelimbic mPFC (Fig. $6 C$ ). Six animals were excluded because cannulas were placed outside the target area. Muscimol or vehicle was infused, and rats were exposed to the adult female rat or cat odor. For the freezing behavior, there was a significant interaction between the treatment and the stimulus type $\left(F_{(3,48)}=6.99\right.$, $p<0.001)$. Post hoc test comparisons showed that inactivation of the infralimbic mPFC did not affect fear behavior (Fig. 6A), whereas rats infused with muscimol into the prelimbic $\mathrm{mPFC}$ froze significantly less when exposed to cat odor than all other groups exposed to the cat odor $(p<0.001)$ (Fig. 6A). There was no significant difference in the female-exposed rats. Inactivation of the prelimbic mPFC did not affect FOS expression in the amygdala or dPAG but reduced FOS expression in the vPAG in the cat odor condition $\left(F_{(3,50)}=4.29, p<0.01\right)$ (Fig. $\left.6 B\right)$. In the 


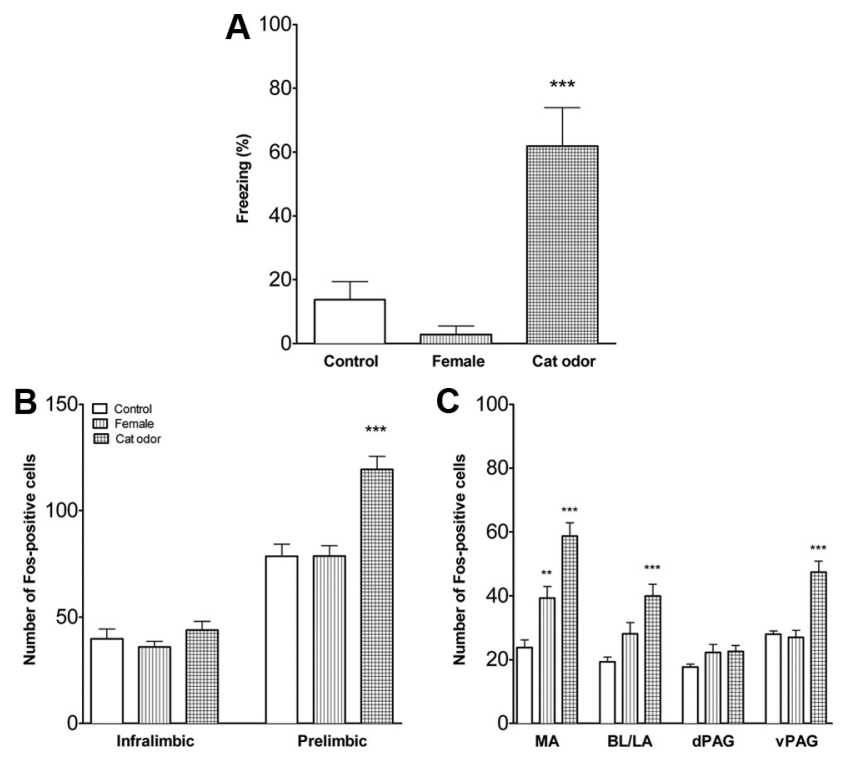

Figure 5. Fear response and brain activation in adolescent rats with intact $m$ PFC. $\boldsymbol{A}$, Percentage time freezing in adolescent rats exposed to an adult female rat or cat fur odor. Controls were exposed to empty cage. Cat-odor-exposed rats froze significantly more than female-exposed or control rats. $n=6-7$ in each condition. $\boldsymbol{B}$, Activation of the $\mathrm{mPFC}$ in adolescent rats with intact $\mathrm{mPFC}$. Number of FOS-positive cells was significantly increased in prelimbic mPFC of rats exposed to the threatening stimulus (cat odor). $n=6$ in each condition. $C$, Activation of the amygdala and PAG in adolescent rats with intact mPFC. Exposure to the threatening stimulus (cat odor) increased the number of FOS-positive cells in the medial and basolateral/lateral amygdala and vPAG, and exposure to the nonthreatening stimulus (adult female) increased FOS in the medial amygdala. MA, Medial amygdala; BL/LA, basolateral/lateral amygdala. ${ }^{* *} p<$ $0.01,{ }^{* *} p<0.001 . n=7$ in each condition.

vPAG, rats infused with muscimol into the prelimbic mPFC and exposed to the cat odor had significantly fewer FOS-positive cells than all other infused groups exposed to the cat odor [post hoc comparisons: vs prelimbic vehicle $(p<0.001)$, vs infralimbic muscimol $(p<0.001)$, and vs infralimbic vehicle $(p<0.01)]$.

To test whether muscimol injection into the prelimbic $\mathrm{mPFC}$ had unspecific effects, behavior during a 3 min period immediately before stimulus presentation (empty experimental compartment) was assessed in muscimol- and vehicle-infused rats. The two groups did not significantly differ in freezing (muscimol, $3.1 \pm 1.2 \%$; vehicle, $3.8 \pm 1.3 \%$ ) or explorative behavior (muscimol, $25.2 \pm 3.3 \%$; vehicle, $30.4 \pm 2.8 \%$ ).

\section{Discussion}

Although young rats respond to threatening stimuli throughout development, the prefrontal cortex does not participate in fear behavior at very young ages but rather becomes progressively functional as the rats mature. By adolescence, the prelimbic mPFC contributes to unlearned fear behavior through modulation of PAG activity.

\section{Infants}

Infant rats froze when exposed to an unfamiliar adult male or cat odor but not to the female rat. Male rats are infanticidal to infants and pose a significant threat but less so to the infant protected in the burrow (Rosenberg, 1974; Brown, 1986; Mennella and Moltz, 1988); lactating females, however, behave maternally toward pups (Beach and Jaynes, 1956). Infant rats thus exhibit a fear response selectively to threatening stimuli and not the unthreatening stimuli. Because the infant rats had no experience with adult male rats or cat odor, their fear response is unlearned and provides immediate protection from high-risk encounters (Wiedenmayer, 2009).

Infant rats detect conspecifics by olfaction (Hepper, 1986; Chen et al., 2006). Chemosensory information is relayed to the amygdala, which is critically involved in the detection and assessment of threatening stimuli (Davis, 2000; LeDoux, 2000; Fanselow and Gale, 2003; Rosen, 2004). Male and female rat exposure activated the medial amygdala in infant rats but cat odor did not. It has been hypothesized that the medial amygdala processes socially relevant stimuli and assesses potential threats; it is considered the major amygdaloid nucleus for social recognition in mammals (Brennan and Kendrick, 2006; Sanchez-Andrade and Kendrick, 2009). Here we found specificity in the medial nucleus, which was activated by a conspecific independently of threat potential but not activated by the cat odor. Whether this is a function of a live stimulus versus an odor or conspecific versus non-conspecific stimuli is not known. Nonetheless, these data imply a developmental continuity in the function of the medial amygdala. The amygdala projects to the PAG, which organizes defensive responding (LeDoux, 2000; Price, 2005). The ventrolateral columns of the PAG mediate passive defensive behaviors, including freezing, whereas the dorsolateral columns mediate active defensive behaviors, such as flight (Keay and Bandler, 2001). Male and cat odor exposure increased FOS expression in the vPAG, consistent with the induction of freezing; lesions of the vPAG decrease male-induced freezing in infant rats (Wiedenmayer et al., 2000). In contrast, there was a small increase in the number of FOS-positive cells in the dorsal PAG, replicating the pattern seen in the medial amygdala.

The two subdivisions of the mPFC were not activated by female or male exposure, and pharmacological inactivation did not affect FOS expression in the amygdala and PAG or the behavioral response. Thus, $\mathrm{mPFC}$ does not play a role in the regulation of unlearned fear in infant rats.

\section{Juveniles}

Adult male rats do not pose an infanticidal threat to young rats after weaning (Paul and Kupferschmidt, 1975). Juvenile rats did not show fear during male exposure but did freeze when exposed to the odor of a natural predator, a cat. Under feral conditions, juvenile rats leave the natal burrow for brief periods of time (Boice, 1977; Galef, 1981), increasing predation risk (Caro, 2005). Juvenile rats thus respond appropriately to the threat of predation, as do adult animals (Apfelbach et al., 2005).

Cat odor increased FOS expression in the same regions of the amygdala and PAG as the adult male did for infant rats and as predator odor does in adult rats (Dielenberg et al., 2001; McGregor et al., 2004; Campeau et al., 2008), indicating developmental continuity in processing threatening stimuli. As in infant rats, the nonthreatening stimulus activated the medial amygdala, demonstrating its role in the processing of ecologically relevant stimuli such as unfamiliar conspecifics. Unexpectedly, the adult male also induced FOS expression in the basolateral amygdala, an area typically involved in association and discrimination learning (Gall et al., 1998; Tronel and Sara, 2002; Kippin et al., 2003; Reijmers et al., 2007). Thus, basolateral activation may reflect the interaction of weaned rats with other colony members as they leave the natal burrow (Calhoun, 1963).

Exposure to cat odor activated the prelimbic but not infralimbic mPFC. This represents a significant change from infant rats and indicates that the $\mathrm{mPFC}$ is engaged in stimulus processing at this later age. However, the $\mathrm{mPFC}$ does not seem to play a role in fear behavior because $\mathrm{mPFC}$ inactivation did not affect amygdala 

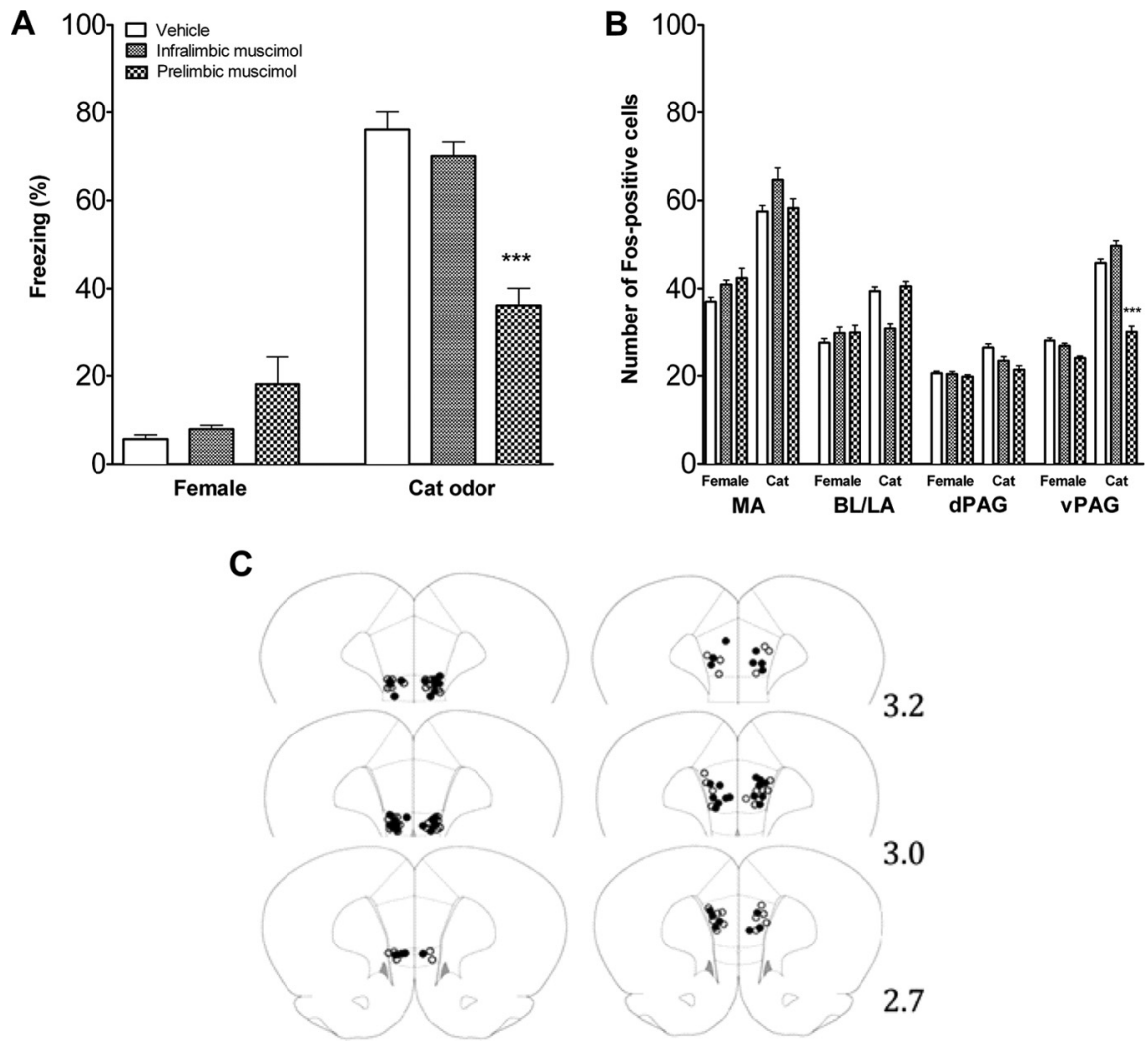

Figure 6. Fear response and brain activation in adolescent rats infused with muscimol or vehicle in $\mathrm{mPFC}$. $\boldsymbol{A}$, Percentage time freezing in adolescent rats infused with vehicle or muscimol in the infralimbic and prelimbic $\mathrm{MPFC}$ and exposed to a nonthreatening female or threatening cat odor (mean \pm SEM). There were no significant differences for rats infused in the infralimbic $m P F C$, but when infused into the prelimbic MPFC, freezing to the cat was significantly reduced. $\boldsymbol{B}$, Number of FOS-positive cells in the amygdala and PAG of adolescent rats injected with vehicle or muscimol into infralimbic or prelimbic mPFC and exposed to a nonthreatening female or threatening cat odor. Mean \pm SEM. FOS expression was selectively reduced in the vPAG only by prelimbic infusion. $n=6-8$ in each condition. C,Cannula placement in infralimbic (left) and prelimbic (right) mPFC of adolescent rats. Open circles represent the location of cannula tips in rats infused with vehicle, and filled circles represent the location of cannula tips in rats infused with muscimol. Numbers indicate the distance in millimeters from bregma. ${ }^{* *} p<0.001$.

or PAG activity or the behavioral response. Whether this is attributable to immaturity of the mPFC, its projections to the amygdala and PAG, or the inability of these latter two structures to respond to $\mathrm{mPFC}$ inputs is not known.

\section{Adolescents}

Adolescent wild rats leave the nest site to forage in novel environments and eventually disperse from the natal area (Calhoun, 1963; Galef, 1981). This transition is facilitated by increased motivation for exploration, novelty seeking, and risk taking (Spear, 2000) but increases vulnerability to predation (Caro, 2005). However, increased activity during adolescence brings young rats in contact with conspecifics other than mother and siblings (Calhoun, 1963; Galef, 1981). Accordingly, adolescent rats froze when exposed to cat odor but not to an unfamiliar female rat, demonstrating the ability to discriminate between threatening and nonthreatening stimuli.

Like juveniles, cat odor exposure increased FOS expression in the prelimbic mPFC, medial amygdala, and vPAG. Similar to infants and juveniles, exposure to the nonthreatening stimulus activated the medial amygdala, again indicating that this nucleus processes not only aversive but more generally ecologically relevant stimuli.

In contrast to infant and juvenile rats, inactivation of the prelimbic $\mathrm{mPFC}$ decreased freezing to threat. Prelimbic $\mathrm{mPFC}$ inac- tivation also reduced FOS expression in the vPAG. Adult animals exposed to predator odor show similar activation patterns (Dielenberg et al., 2001; McGregor et al., 2004; Campeau et al., 2008). There are, however, also differences: predator odor induced FOS expression in the infralimbic mPFC (Staples et al., 2008) and the basolateral amygdala (Campeau et al., 2008; Staples et al., 2008) in the adult but not the adolescent. Therefore, the adolescent $\mathrm{mPFC}$ is not fully mature.

\section{Fear regulation across ages}

The mPFC progressively matures during early ontogeny and becomes functional in adolescence in which it mediates an unlearned fear response to an ecologically relevant threat. Our data suggest a nuanced process by which the MPFC continues to mature even through adolescence to engage more caudal structures and to modify freezing. Few other studies have examined the role of the mPFC in unlearned fear, and those findings are not conclusive. Inactivation of the prelimbic $\mathrm{mPFC}$ by tetrodotoxin infusion in adult rats through a cannula placed between the two hemispheres did not affect freezing to a cat or open-field activity (Corcoran and Quirk, 2007). This inactivation may be sufficient to block learned but not unlearned fear. Lesion studies have also produced mixed results. Prelimbic mPFC lesion in rats reduced (Maaswinkel et al., 1996) or increased (Jinks and McGregor, 1997) anxiety in the elevated plus maze, increased anxiety in the open-field test (Jinks and McGregor, 1997), or had no effect (Burns et al., 1996; Maaswinkel et al., 1996). Lesion of both the infralimbic and prelimbic mPFC decreased fear behavior in the elevated plus maze and open field (Lacroix et al., 2000). It remains to be investigated what features of a threatening situation are processed by the $\mathrm{mPFC}$ and what response patterns are regulated by it.

The accepted model of fear regulation is based on adult animals that possess a fully matured mPFC. In young animals, the $\mathrm{mPFC}$ is maturing and the existent neural circuitry regulates behavior specific for that age and ontogenetic niche. Components are added as the animal matures, leaves the protection of the nest, and requires more complicated circuitry to allow for survival.

The mPFC did not play a role in unlearned fear in infant or juvenile rats. Even in the absence of a fully functional mPFC, pups froze to the threat on first exposure. Other areas of the fear circuit must mediate differential fear responsiveness at these ages. A possible $\mathrm{mPFC}$-independent mechanism could involve subpopulations of neurons within the medial amygdala. Female and male odors activate different subdivisions of the medial amygdala in male rodents, indicating regional specialization of neurons in odor classification (Samuelsen and Meredith, 2009; Donato et al., 2010). Alternatively, other areas that were not examined here but have been implicated in unlearned fear (Mongeau et al., 2003; Engin and Treit, 2008) could contribute to the expression of freezing. 
Finally, the model of mPFC fear regulation predicts that fear is promoted or inhibited through mPFC effects on amygdala, which in turn activates the PAG to coordinate both the physiological and behavioral responses to potential threats (An et al., 1998; Floyd et al., 2000; Keay and Bandler, 2001; Gabbott et al., 2005). The PAG matures within the developmental timeframe that requires the animal to engage in defensive behavior. Lesions of the ventral PAG but not the lateral PAG suppressed freezing to a unfamiliar male rat at $14 \mathrm{~d}$ of age and injection of either kainate or a $\kappa$-opioid agonist enhanced defensive behavior at 14 but not $7 \mathrm{~d}$ of age (Goodwin and Barr, 1998; Wiedenmayer et al., 2000; Goodwin and Barr, 2005). Here, the PAG showed higher levels of FOS expression in the infants to the appropriate threat, consistent with previous work (Wiedenmayer and Barr, 2001). Therefore, we hypothesize that the PAG is poised first to engage in defense by the end of the second week of life.

In conclusion, the "fear" circuit develops in a complex stepwise manner with the amygdala and PAG serving this function in infants. The prelimbic mPFC is activated for the first time in juvenile animals but does not participate fully in the circuit until adolescence.

\section{References}

An X, Bandler R, Ongür D, Price JL (1998) Prefrontal cortical projections to longitudinal columns in the midbrain periaqueductal gray in macaque monkeys. J Comp Neurol 401:455-479.

Apfelbach R, Blanchard CD, Blanchard RJ, Hayes RA, McGregor IS (2005) The effects of predator odors in mammalian prey species: a review of field and laboratory studies. Neurosci Biobehav Rev 29:1123-1144.

Beach FA, Jaynes J (1956) Studies of maternal retrieving in rats. I. Recognition of young. J Mammal 37:177-180.

Benes FM, Taylor JB, Cunningham MC (2000) Convergence and plasticity of monoaminergic systems in the medial prefrontal cortex during the postnatal period: Implications for the development of psychopathology. Cereb Cortex 10:1014-1027.

Boice R (1977) Burrows of wild and albino rats: effects of domestication, outdoor raising, age, experience, and maternal state. J Comp Physiol Psychol 91:649-661.

Brennan PA, Kendrick KM (2006) Mammalian social odours: attraction and individual recognition. Phil Trans R Soc B Biol Sci 361:2061-2078.

Bronson GW (1968) The development of fear in man and other animals. Child Dev 39:409-431.

Brown RE (1986) Social and hormonal factors influencing infanticide and its suppression in adult male Long-Evans rats. J Comp Psychol 100:155-161.

Burns LH, Annett L, Kelley AE, Everitt BJ, Robbins TW (1996) Effects of lesions to amygdala, ventral subiculum, medial prefrontal cortex, and nuccleus accumbens on the reaction to novelty: implication for limbicstriatal interactions. Behav Neurosci 110:60-73.

Calhoun JB (1963) The ecology and sociology of the Norway rat. Bethesda, MD: U.S. Department of Health, Education, and Welfare.

Campeau S, Nyhuis TJ, Sasse SK, Day HE, Masini CV (2008) Acute and chronic effects of ferret odor exposure in Sprague-Dawley rats. Neurosci Biobehav Rev 32:1277-1286.

Caro T (2005) Antipredator defenses in birds and mammals. Chicago: The University of Chicago.

Chen SW, Shemyakin A, Wiedenmayer CP (2006) The role of the amygdala and olfaction in unconditioned fear in developing rats. J Neurosci 26:233-240.

Coggeshall RE, Lekan HA (1996) Methods for determining numbers of cells and synapses: a case for more uniform standards of review. J Comp Neurol 364:6-15.

Corcoran KA, Quirk GJ (2007) Activity in prelimbic cortex is necessary for the expression of learned, but not innate, fears. J Neurosci 27:840-844.

Curio E (1993) Proximate and developmental aspects of antipredator behavior. In: Advances in the study of behavior (Slater PJB, Rosenblatt JS, Snowdon CT, Milinski M, eds), pp 135-238. San Diego: Academic.

Davis M (2000) The role of the amygdala in conditioned and unconditioned fear and anxiety. In: The amygdala, Ed 2 (Aggleton JP, ed), pp 213-287. Oxford: Oxford UP.

Deschamps S, Woodside B, Walker CD (2003) Pups presence eliminates the stress hyporesponsiveness of early lactating females to a psychological stress representing a threat to the pups. J Neuroendocrinol 15:486-497.

Dielenberg RA, Hunt GE, McGregor IS (2001) "When a rat smells a cat": the distribution of Fos immunoreactivity in rat brain following exposure to a predatory odor. Neuroscience 104:1085-1097.

Donato J Jr, Cavalcante JC, Silva RJ, Teixeira AS, Bittencourt JC, Elias CF (2010) Male and female odors induce Fos expression in chemically defined neuronal population. Physiol Behav 99:67-77.

Engin E, Treit D (2008) The effects of intra-cerebral drug infusions on animals' unconditioned fear reactions: a systematic review. Prog Neuropsychopharmacol Biol Psychiatry 32:1399-1419.

Fanselow MS, Gale GD (2003) The amygdala, fear, and memory. Ann NY Acad Sci 985:125-134.

Floyd NS, Price JL, Ferry AT, Keay KA, Bandler R (2000) Orbitomedial prefrontal cortical projections to distinct longitudinal columns of the periaqueductal gray in the rat. J Comp Neurol 422:556-578.

Gabbott PL, Warner TA, Jays PR, Salway P, Busby SJ (2005) Prefrontal cortex in the rat: projections to subcortical autonomic, motor, and limbic centers. J Comp Neurol 492:145-177.

Galef BG (1981) The ecology of weaning. In: Parental care in mammals (Gubernick DJ, Klopfer PH, eds), pp 211-241. New York: Plenum.

Gall CM, Hess US, Lynch G (1998) Mapping brain networks engaged by, and changed by, learning. Neurobiol Learn Mem 70:14-36.

Goodwin GA, Barr GA (1998) Behavioral and heart rate effects of infusing kainic acid into the dorsal midbrain during early development in the rat. Brain Res Dev Brain Res 107:11-20.

Goodwin GA, Barr GA (2005) Developmental changes in the behavioral and autonomic effects of kappa opioid receptor stimulation of the midbrain periaqueductal gray. Dev Psychobiol 46:47-56.

Hennessy MM, Weinberg J (1990) Adrenocortical activity during conditions of brief social separation in preweaning rats. Behav Neural Biol 54:42-55.

Hepper PG (1986) Parental recognition in the rat. Q J Exp Psychol 38B:151-160

Hofer MA, Shair H (1980) Sensory processes in the control of isolationinduced ultrasonic vocalization by 2 -week-old rats. J Comp Physiol Psychol 94:271-279.

Jinks AL, McGregor IS (1997) Modulation of anxiety-related behaviours following lesions of the prelimbic or infralimbic cortex in the rat. Brain Res 772:181-190.

Keay KA, Bandler R (2001) Parallel circuits mediating distinct emotional coping reactions to different types of stress. Neurosci Biobehav Rev 25:669-678.

Kim JH, Hamlin AS, Richardson R (2009) Fear extinction across development: the involvement of the medial prefrontal cortex as assessed by temporary inactivation and immunohistochemistry. J Neurosci 29:10802-10808.

Kippin TE, Cain SW, Pfaus JG (2003) Estrous odors and sexually conditioned neutral ordors activate separate neural pathways in the male rat. Neuroscience 117:971-979.

Lacroix L, Spinelli S, Heidbreder CA, Feldon J (2000) Differential role of the medial and lateral prefrontal cortices in fear and anxiety. Behav Neurosci 114:1119-1130

LeDoux JE (2000) Emotion circuits in the brain. Annu Rev Neurosci 23:155-184

Maaswinkel H, Gispen WH, Spruijt BM (1996) Effects of an electrolytic lesion of the prelimbic area on anxiety-related and cognitive tasks in the rat. Behav Brain Res 79:51-59.

McGregor IS, Hargreaves GA, Apfelbach R, Hunt GE (2004) Neural correlates of cat odor-induced anxiety in rats: region-specific effects of the benzodiazepine midazolam. J Neurosci 24:4134-4144.

Mennella JA, Moltz H (1988) Infanticide in rats: male strategy and female counter-strategy. Physiol Behav 42:19-28.

Mongeau R, Miller GA, Chiang E, Anderson DJ (2003) Neural correlates of competing fear behaviors evoked by an innately aversive stimulus. J Neurosci 23:3855-3868.

Morgan JI, Curran T (1991) Stimulus-transcription coupling in the nervous system: involvement of the inducible proto-oncogenes fos and jun. Annu Rev Neurosci 14:421-451. 
Neumann ID, Toschi N, Ohl F, Torner L, Krömer SA (2001) Maternal defence as an emotional stressor in female rats: correlation of neuroendocrine and behavioural parameters and involvement of brain oxytocin. Eur J Neurosci 13:1016-1024.

Öhman A, Mineka S (2001) Fears, phobias, and preparedness: towards an evolved module of fear and fear learning. Biol Rev 108:483-522.

Paré D, Quirk GJ, Ledoux JE (2004) New vistas on amygdala networks in conditioned fear. J Neurophysiol 92:1-9.

Paul L, Kupferschmidt J (1975) Killing of conspecific and mouse young by male rats. J Comp Physiol Psychol 88:755-763.

Paxinos G, Watson C (2007) The rat brain in stereotaxic coordinates, Ed 6. San Diego: Academic.

Peters J, Kalivas PW, Quirk GJ (2009) Extinction circuits for fear and addiction overlap in prefrontal cortex. Learn Mem 16:279-288.

Price JL (2005) Free will versus survival: brain systems that underlie intrinsic constraints on behavior. J Comp Neurol 493:132-139.

Reijmers LG, Perkins BL, Matsuo N, Mayford M (2007) Localization of a stable neural correlate of associative memory. Science 317:1230-1233.

Rosen JB (2004) The neurobiology of conditioned and unconditioned fear: a neurobehavioral system analysis of the amygdala. Behav Cogn Neurosci $\operatorname{Rev} 3: 23-41$.

Rosenberg KM (1974) Effects of pre- and postpubertal castration and testosterone on pup-killing behavior in the male rat. Physiol Behav 13:159-161

Samuelsen CL, Meredith M (2009) Categorization of biologically relevant chemical signals in the medial amygdala. Brain Res 1263:33-42.

Sanchez-Andrade G, Kendrick KM (2009) The main olfactory system and social learning in mammals. Behav Brain Res 200:323-335.

Spear LP (2000) The adolescent brain and age-related behavioral manifestations. Neurosci Biobehav Rev 24:417-463.
Staples LG, McGregor IS, Apfelbach R, Hunt GE (2008) Cat odor, but not trimethylthiazoline (fox odor), activates accessory olfactory and defenserelated brain regions in rats. Neuroscience 151:937-947.

Thor DH, Flannelly KJ (1976) Age of intruder and territorial-elicited aggression in male Long-Evans rats. Behav Biol 17:237-241.

Tronel S, Sara SJ (2002) Mapping of olfactory memory circuits: Regionspecific c-fos activation after odor-reward associative learning or after its retrieval. Learn Mem 9:105-111.

Ulrich-Lai YM, Herman JP (2009) Neural regulation of endocrine and autonomic stress responses. Nat Rev Neurosci 10:397-409.

van Eden CG, Kros JM, Uylings HB (1990) The development of the rat prefrontal cortex. Prog Brain Res 85:169-183.

van Schaik CP, Janson $\mathrm{CH}$, eds (2000) Infanticide by males and its implications. Cambridge, UK: Cambridge UP.

Vidal-Gonzalez I, Vidal-Gonzalez B, Rauch SL, Quirk GJ (2006) Microstimulation reveals opposing influences of prelimbic and infralimbic cortex on the expression of conditioned fear. Learn Mem 13:728-733.

Wiedenmayer CP (2009) Plasticity of defensive behavior and fear in early development. Neurosci Biobehav Rev 33:432-441.

Wiedenmayer CP, Barr GA (2001) Developmental changes in c-fos expression to an age-specific social stressor in infant rats. Behav Brain Res 126:147-157.

Wiedenmayer CP, Goodwin GA, Barr GA (2000) The effect of periaqueductal gray lesions on responses to age-specific threats in infant rats. Brain Res Dev Brain Res 120:191-198.

Wiedenmayer CP, Magariños AM, McEwen BS, Barr GA (2005) Agespecific threats induce CRF expression in the paraventricular nucleus of the hypothalamus and hippocampus of young rats. Horm Behav 47:139150 . 